\title{
Pseudomonas paucimobilis, a New Species Isolated from Human Clinical Specimens, the Hospital Environment, and Other Sources
}

\author{
B. HOLMES, R. J. OWEN, ANDREA EVANS, H. MALNICK, AND W. R. WILLCOX \\ National Collection of Type Cultures, Central Public Health Laboratory, London NW9 5 HT, United Kingdom
}

Forty-seven strains of yellow-pigmented, non-fermentative, gram-negative, rod-shaped bacteria isolated from clinical specimens (14 strains), the hospital environment ( 20 strains), and miscellaneous sources (13 strains) were characterized with respect to 68 phenotypic tests. The results, along with those of the same 68 tests carried out on 51 reference strains that represented species of Pseudomonas and six other genera of gram-negative bacteria, were analyzed by numerical taxonomic methods. Twenty-nine of the 47 yellow-pigmented strains, including two strains of Weaver group IIk, biotype 1, formed a homogeneous phenetic group (within-group similarity: $93.4 \% \mathrm{~S}_{G}$ ). The group consisted of strictly aerobic, heterotrophic rod-shaped bacteria. Cells were motile by means of a single polar flagellum. Only a few of the cells were actively motile in nutrient broth cultures, so this characteristic was often difficult to demonstrate. The strains were homogeneous in their susceptibilities to antimicrobial agents, and the mean guanine-plus-cytosine content of the deoxyribonucleic acids from 13 of the isolates was $64.9 \pm 1.4 \mathrm{~mol} \%$. The 29 strains conformed to the general characteristics of the genus Pseudomonas. The reasons for excluding the strains from Xanthomonas are discussed. We consider these strains to represent a new species, for which we propose the name Pseudomonas paucimobilis. The type strain of the new species is CL1/70 (=NCTC 11030). The remaining 18 yellowpigmented isolates were unclassified except for two strains which corresponded to a Flavobacterium sp. (King group IIb).

In a number of studies $(15,20,24,28,29,32$, 34,35 ), the isolation of yellow-pigmented bacteria, frequently described as xanthomonad- or pseudomonad-like in their characteristics, has been reported from human clinical specimens and from sources in the hospital environment. The pathogenicity for man of these bacteria has not been proved $(28,34,35)$.

The pseudomonad-like strains from human sources described by Tatum et al. (32) were referred to as group IIk and divided into biotypes 1 and 2 . The choice of biochemical tests suitable for the identification of group $\Pi \mathrm{k}$ isolates and xanthomonads was investigated by von Graevenitz $(33,34)$, who found that these bacteria could be distinguished from most of the clinically important species of Pseudomonas. However, von Graevenitz $(33,34)$ and Tatum et al. (32) did not propose a name for biotypes 1 and 2 of group IIk, and a named species to which they might belong was not suggested.

Over the past 10 years, a number of the yellow-pigmented isolates received in the National Collection of Type Cultures (NCTC) for identification have shown similarities to xanthomonads and to the group IIk isolates. In the present study, a numerical analysis of phenotypic characteristics, the effect of antimicrobial agents, and determinations of deoxyribonucleic acid (DNA) base compositions have been used to investigate the taxonomic relationships of these yellow-pigmented microorganisms. Evidence is presented that 29 of the isolates constitute a new species of Pseudomonas.

\section{MATERIALS AND METHODS}

Bacterial strains. The 98 bacterial strains studied (Table 1) comprised: 27 strains of the new species; 16 miscellaneous, unclassified, yellow-pigmented isolates; and 55 reference strains representing biotypes 1 and 2 of Weaver group IIk and species of the genera Acinetobacter, Alcaligenes, Bordetella, Chromobacterium, Flavobacterium, Pseudomonas, and Xanthomonas.

Bacteriological investigations. The bacteria were maintained on nutrient agar (Oxoid nutrient broth powder CM 67, $25 \mathrm{~g}$, and New Zealand agar, $12 \mathrm{~g}$ per litre of distilled watęr) under aerobic conditions and were tested at their optimum growth temperature, usually $37^{\circ} \mathrm{C}$ but in some cases $30^{\circ} \mathrm{C}$ or room temperature $\left(18\right.$ to $\left.22^{\circ} \mathrm{C}\right)$. Anaerobic growth was tested on nutrient agar by incubation for 2 days in a McIntosh and Fildes jar filled with $90 \% \mathrm{H}_{2}$ and $10 \% \mathrm{CO}_{2}$. The 
TABLE 1. Bacterial strains studied

\begin{tabular}{|c|c|c|c|}
\hline Organism/strain no. & Isolated from: & Organism (reference strains) & Strain no. ${ }^{a}$ \\
\hline $\begin{array}{l}\text { Pseudomonas paucimobilis } \\
\text { sp. nov. }\end{array}$ & & Acinetobacter anitratus & NCTC $7844^{\circ}$ \\
\hline CL246/69 & Incubator water; Derby, England & Acinetobacter lwoffii & NCTC $5866^{b}$ \\
\hline \multirow{4}{*}{$\begin{array}{l}\text { CL1/70, CL162/70, } \\
\text { CL173/70, CL311/70, } \\
\text { CL15/71, CL135/72, } \\
\text { CL136/72 }\end{array}$} & Respirators; London, England, St. & Alcaligenes odorans & NCTC $10416^{b}$ \\
\hline & Thomas' Hospital & Bordetella bronchiseptica & NCTC $452^{b}$ \\
\hline & & Chromobacterium lividum & NCTC $9796^{\circ}$ \\
\hline & & Flavobacterium breve & ATCC 14234 \\
\hline CL13/70 & Blood culture; Aberdeen, Scotland & Flavobacterium ferrugineum & ATCC 13524 \\
\hline CL310/70 & $\begin{array}{l}\text { Tracheostomy site; London, Eng- } \\
\text { land, St. Thomas' Hospital }\end{array}$ & $\begin{array}{l}\text { Flavobacterium heparinum } \\
\text { Flavobacterium meningosepticum }\end{array}$ & $\begin{array}{l}\text { ATCC } 13125 \\
\text { NCTC } 10016^{b}\end{array}$ \\
\hline \multirow[t]{2}{*}{ CL50/72 } & Darrow solution; Shrewsbury, Eng- & Flavobacterium meningosepticum & NCTC 10585 \\
\hline & land & Flavobacterium odoratum & ATCC 4651 \\
\hline CL623/72 & Blood culture; Maidstone, England & Flavobacterium pectinovorum & ATCC $19366^{b}$ \\
\hline \multirow[t]{2}{*}{ CL158/74 } & Ventilator humidifier; Guildford, & Flavobacterium group Ilb & NCTC 10795 \\
\hline & & Flavobacterium group IIb & NCTC 10796 \\
\hline A12/65 & Vaginal swab; Ipswich, England & Flavobacterium group IIf & NCTC 10798 \\
\hline \multirow[t]{2}{*}{$\mathrm{A} 47 / 65$} & Monkey kidney tissue culture; Lon- & Flavobacterium group IIf & NCTC 10799 \\
\hline & don, England & Pseudomonas acidovorans & NCTC 10683 \\
\hline A32/67 & Drainage bottle; Southend, England & Pseudomonas aeruginosa & NCTC $10332^{b}$ \\
\hline A90/67 & Air, surgical unit; Germany & Pseudomonas alcaligenes & NCTC $10367^{b}$ \\
\hline A74/68 & Tap water; Birmingham, England & Pseudomonas aureofaciens & NCTC $10686^{b}$ \\
\hline A92/68, A93/68 & Mink tissue; Inverness, Scotland & Pseudomonas cepacia & NCTC 10661 \\
\hline \multirow[t]{2}{*}{ A96/68, A97/68 } & Water, theater sterile water plant; & Pseudomonas cepacia & NCTC 10734 \\
\hline & Inverness, Scotland & Pseudomonas cepacia & NCTC $10743^{b}$ \\
\hline A119/68 & Respirator; Glasgow, Scotland & Pseudomonas kingii & NCTC $10744^{b}$ \\
\hline \multirow[t]{2}{*}{$\mathrm{A} 102 / 70$} & Swimming pool water; Birmingham, & Pseudomonas chlororaphis & NCTC 7357 \\
\hline & England & Pseudomonas diminuta & NCTC $8545^{b}$ \\
\hline A129/72 & Blood culture; Portsmouth, England & Pseudomonas fluorescens & NCTC $10038^{b}$ \\
\hline F92 & Urine; Nantwich, England & Pseudomonas fragi & NCTC $10689^{b}$ \\
\hline F143 & Cervical swab; Portsmouth, England & Pseudomonas lemoignei & NCTC $10937^{b}$ \\
\hline \multirow{2}{*}{$\begin{array}{l}\text { B3271 group IIk, bio- } \\
\text { type } 1\end{array}$} & Spinal fluid; Center for Disease Con- & Pseudomonas mallei & NCTC $10230^{b}$ \\
\hline & trol Atlanta $\mathrm{Go}$ & Pseudomonas maltophilia & NCTC $10257^{b}$ \\
\hline \multirow{2}{*}{$\begin{array}{l}\text { B4562 group IIk, bio- } \\
\text { type } 1\end{array}$} & Blood culture; Center for Disease & Pseudomonas maltophilia & $\mathrm{CL} 24 / 70^{c}$ \\
\hline & Control, Atlanta, Ga. & Pseudomonas maltophilia & $\mathrm{CL} 297 / 70^{c}$ \\
\hline \multicolumn{2}{|l|}{ Unclassified strains } & Pseudomonas mendocina & NCTC $10897^{b}$ \\
\hline CL252/70 & Renal dialysate; Derby, England & Pseudomonas mendocina & NCTC 10898 \\
\hline CL361/70 & Respirator; London, England & Pseudomonas pseudoalcaligenes & NCTC $10860^{b}$ \\
\hline CL263/70 & Dialysis fluid; London, England & Pseudomonas pseudomallei & NCTC $4845^{b}$ \\
\hline CL514/72 & Glucose solution; London, England & Pseudomonas putida & NCTC $10936^{b}$ \\
\hline CL577/72 & Blood culture; London, England & Pseudomonas putrefaciens & NCTC 10735 \\
\hline CL309/73 & Blood culture; Birmingham, England & Pseudomonas stutzeri & NCTC 10450 \\
\hline CL314/73 & Tongue swab; London, England & Pseudomonas stutzeri & NCTC 10473 \\
\hline CL475/73 & Pus; Dar-es-Salaam, Tanzania & Pseudomonas stutzeri & NCTC $10475^{b}$ \\
\hline A14/65 & Wound swab; Nottingham, England & Pseudomonas stutzeri & $\mathrm{A} 75 / 66^{c}$ \\
\hline A19/66 & Plant swab; London, England & Pseudomonas taetrolens & NCTC $10697^{b}$ \\
\hline A77/68 & Plant swab; Dorchester, England & Pseudomonas testosteroni & NCTC $10698^{b}$ \\
\hline A80/68 & $\mathrm{NaHCO}_{3}$ solution; Watford, England & Pseudomonas thomasii & NCTC 10894 \\
\hline A95/68 & Tissue culture; Inverness, Scotland & Pseudomonas vesicularis & NCTC $10900^{b}$ \\
\hline \multirow[t]{2}{*}{$\mathrm{A} 100 / 68$} & Water basin overflow; Shoreham, & Xanthomonas campestris & NCPPB 528 \\
\hline & & Xanthomonas campestris & NCPPB 45 \\
\hline E894 & NCIB, Aberdeen, Scotland & Xanthomonas hyacinthi & NCPPB $599^{b}$ \\
\hline F141 & Fingernail; Portsmouth, England & Xanthomonas hyacinthi & NCPPB 1622 \\
\hline $\begin{array}{l}\text { A8895 group IIk, bio- } \\
\text { type } 2\end{array}$ & $\begin{array}{l}\text { Serous cavity fluid; Center for Dis- } \\
\text { ease Control, Altanta, Ga. }\end{array}$ & & \\
\hline B3159 group IIk, bio- & Blood culture; Center for Disease & & \\
\hline type 2 & Control, Atlanta, Ga. & & \\
\hline
\end{tabular}

${ }^{a}$ Key to sources: NCTC, National Collection of Type Cultures, Central Public Health Laboratory, London NW9 5HT, England; ATCC, American Type Culture Collection, Rockville, Md.; NCPPB, National Collection of Plant Pathogenic Bacteria, Harpenden, Hertfordshire, England; CDC, R. E. Weaver, Center for Disease Control, Atlanta, Ga.; NCIB, National Collection of Industrial Bacteria, Torry Research Station, Aberdeen AB9 8DG, Scotland.

${ }^{b}$ Type or suggested type strain.

${ }^{c}$ Stock cultures, originally submitted to the NCTC for identification.

ability of selected strains to grow autotrophically in an atmosphere of hydrogen was tested at the German Collection of Microorganisms (DSM), Göttingen, West Germany, through the kindness of Dr. D. Claus, on a basal minimal medium that contained, per litre of distilled water: $\mathrm{KH}_{2} \mathrm{PO}_{4}, 2.3 \mathrm{~g} ; \mathrm{Na}_{2} \mathrm{HPO}_{4}$.
$2 \mathrm{H}_{2} \mathrm{O}, 2.9 \mathrm{~g} ; \mathrm{NH}_{4} \mathrm{Cl}, 1.0 \mathrm{~g} ; \mathrm{MgSO}_{4} \cdot 7 \mathrm{H}_{2} \mathrm{O}, 0.5 \mathrm{~g}$; $\mathrm{NaHCO}_{3}, 0.5 \mathrm{~g} ; \mathrm{CaCl}_{2} \cdot 2 \mathrm{H}_{2} \mathrm{O}, 0.01 \mathrm{~g}$; and $\mathrm{Fe}\left(\mathrm{NH}_{4}\right)$ citrate, $0.05 \mathrm{~g}$. The $\mathrm{Fe}\left(\mathrm{NH}_{4}\right)$ citrate $(0.05 \mathrm{~g}$ in $20 \mathrm{ml}$ of distilled water) was sterilized separately and then added. Cultures were incubated at $30^{\circ} \mathrm{C}$ for periods up to 8 days in a gas mixture of $60 \% \mathrm{H}_{2}, 10 \% \mathrm{CO}_{2}$, 
$25 \% \mathrm{~N}_{2}$, and $5 \% \mathrm{O}_{2}$. The ability to grow autotrophically under microaerophilic conditions was tested for in the presence of $1 \% \mathrm{O}_{2}$ (a partial pressure of 0.05 atmosphere of oxygen). Colonial morphology was described from aerobic growth on nutrient agar, and hemolysis was recorded on $5 \%(\mathrm{vol} / \mathrm{vol})$ horse blood agar. Pigmentation was recorded from growth on nutrient and tyrosine agars, and fluorescence was tested for on medium B of King et al. (18). The Gram reaction was determined by Lillie's modification as described by Cowan (5). Motility was tested by the hanging-drop method on overnight cultures grown at room temperature $\left(18\right.$ to $\left.22^{\circ} \mathrm{C}\right)$ and at $37^{\circ} \mathrm{C}$ in nutrient broth (Oxoid CM 67), and at room temperature in the mineral base medium of Ayers, Rupp, and Johnson (ARJ base) as modified by Burnett et al. (3) with added $1 \%$ (wt/vol) glucose and $0.1 \%$ (wt/vol) yeast extract. As the proportion of motile bacteria in nutrient broth medium was low, strains of the new species were cultured in ARJ yeast extract medium to enhance bacterial growth and to obtain a greater number of motile cells for the staining of flagella in the preparation of electron microscope grids. The presence of flagella and their arrangement was examined with an electron microscope after staining with $1 \%$ (wt/vol) phosphotungstic acid. Cultures of some strains were also tested on semisolid nutrient agar (Oxoid nutrient broth powder CM 67, $25 \mathrm{~g}$, and Oxoid no. 1 agar, $25 \mathrm{~g}$ per litre of distilled water) in petri dishes to increase selectively the proportion of motile cells.

The biochemical characteristics investigated are listed in Table 2, and the methods used have been described previously by Holmes et al. (17), but the following changes or additions were made. Indole production was tested with Kovacs reagent and with Ehrlich reagent, the latter by method 3 of Cowan (5). To determine if the minimal growth requirements of strains were complex (10), the ARJ mineral base medium with added $1 \%$ (wt/vol) glucose was used. Yeast extract $(0.1 \%$ [wt/vol]) was included in the medium for a positive control. The utilization of $0.2 \%$ (wt/vol) L-asparagine (BDH Chemicals Ltd, Poole, England) as the sole source of carbon and nitrogen was determined by the method of Dye (9). Growth inhibition by $0.1 \%$ (wt/vol) 2,3,5-triphenyltetrazolium chloride (TTC; Koch-Light Laboratories Ltd, Colnbrook, England) was tested by incorporation of the TTC in nutrient agar (10).

Antibiotics were incorporated in paper strips (1) or disks (Mast Laboratories Ltd, Liverpool, England), and susceptibility was tested on Diagnostic Sensitivity Test (DST) agar base (Oxoid CM 261) with added $0.25 \%$ (vol/vol) lysed horse blood. The antibiotics used were (for concentrations, see Table 2) amoxicillin, ampicillin, carbenicillin, cephalexin, chloramphenicol, colistin, erythromycin, gentamicin, kanamycin, nalidixic acid, novobiocin, penicillin G, streptomycin, and tetracycline. Susceptibility to polymyxin $B$ was tested on nutrient agar in which the antibiotic had been incorporated. Disks of vibriostatic agent 0/129 (2,4-diamino-6,7-diisopropyl pteridine phosphate; $\mathrm{BDH}$ ) were prepared from an aqueous solution $(1 \mu \mathrm{g} / \mathrm{ml})$, and the tests for susceptibility were performed on nutrient agar.
Computation of data. A total of 64 of the 88 characteristics listed in Table 2 were used in the numerical analysis. Of the remaining 24 characteristics, some were not used because all 98 strains were either positive (catalase activity) or negative (indole production tested for with Kovacs reagent, gas from glucose, and production of 3-ketolactose) and some were not used because they were additional characteristics determined only on the 29 strains of the new species (determination of complexity of minimal growth requirements, utilization of L-asparagine, inhibition by TTC, anaerobic growth, and susceptibility to the 16 antimicrobial agents).

The majority of tests were treated as two-state characters, and the results were coded as + or (moderately positive results, recorded as \pm , were coded as +; weakly positive results, recorded as $\mp$, were coded as -). For two-state related tests, implied negative results were coded as no-comparison (30). The Hugh and Leifson oxidation-fermentation (O-F) test and colony pigmentation were treated as qualitative multistate characters, and the test results for gelatinase production (the stab and plate methods) were combined to give a single quantitative multistate character (both methods negative $=$ 1 , plate only positive $=2$, both methods positive $=$ $3)$. The between-strain similarities were calculated using Gower's (12) general similarity coefficient $\left(\mathbf{S}_{G}\right.$ in the notation of Sneath and Sokal [30]), and negative matches were included for the two-state characters. The strains were clustered by median-sorting cluster analysis $(11,30)$ and by single-linkage cluster analysis (30); in addition, a minimum spanning tree $(13,30)$ was constructed. Programs developed at the NCTC were used. The median organism of the new taxon was determined (19), and the within- and between-taxon average similarities were calculated as arithmetic means of the relevant similarities.

DNA isolation. The strains were grown overnight at $30^{\circ} \mathrm{C}$ on nutrient agar or in nutrient broth with aeration at $200 \mathrm{rpm}$ in an orbital incubator (Gallenkamp Ltd, London). The bacterial cells were collected by centrifugation, suspended in $0.15 \mathrm{M} \mathrm{NaCl}$ and $0.10 \mathrm{M}$ ethylenediaminetetraacetic acid at $\mathrm{pH}$ 8.0 , and lysed with $2 \%$ (wt/vol) sodium lauryl sulfate at $60^{\circ} \mathrm{C}$ for $15 \mathrm{~min}$. The DNA was extracted and purified by the method of Marmur (22), which was supplemented by treatment for $1 \mathrm{~h}$ at $37^{\circ} \mathrm{C}$ with selfdigested Pronase (Koch-Light Laboratories Ltd, Colnbrook) at a concentration of $50 \mu \mathrm{g} / \mathrm{ml}$.

DNA base composition. The DNA base composition, expressed as moles percent guanine and cytosine $(\mathrm{mol} \% \mathrm{G}+\mathrm{C})$ to total bases, was estimated from the thermal denaturation temperature $\left(T_{m}\right)$, which was determined by the method of Marmur and Doty (23). Thermal denaturation of DNA was carried out in a Pye Unicam SP 1800 spectrophotometer equipped with an SP 876 series 2 temperature program controller and heated cell block. The absorbance changes at $260 \mathrm{~nm}$ were recorded on a Pye Unicam AR 25 linear recorder. The temperature of the DNA solution was measured in the cuvette with a thermistor thermometer (16). The mol\% G+C was calculated from the $T_{m}$ determined in $0.015 \mathrm{M} \mathrm{NaCl}$ buffered with $0.0015 \mathrm{M}$ trisodium citrate at $\mathrm{pH} 7.0$ 


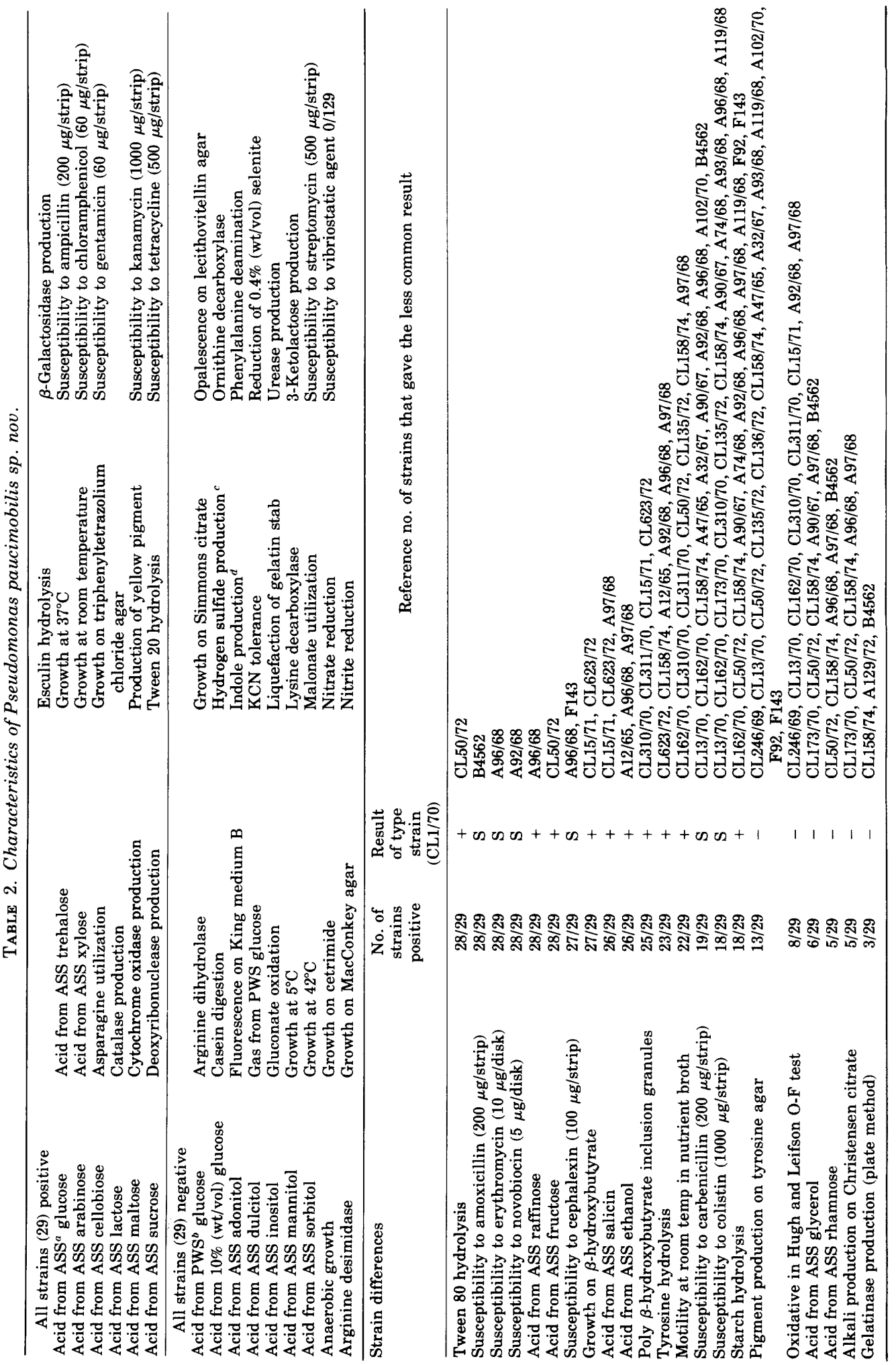




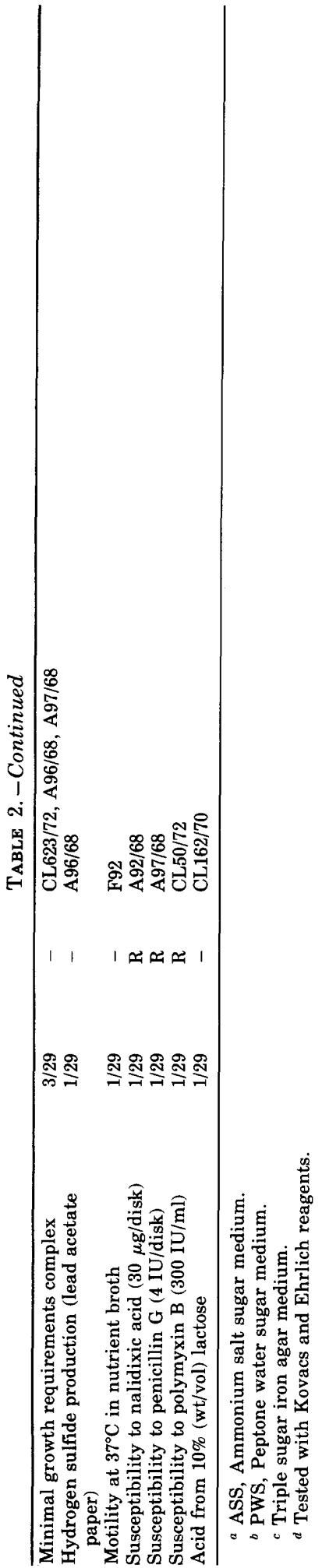

by the equation $\mathrm{mol} \% \mathrm{G}+\mathrm{C}=2.08 T_{m}-106.4$, which was derived from the general equation of Owen et al. (26).

Absorbance spectra of pigments. The bacterial cells were grown and harvested as described for DNA isolation but were suspended and washed with distilled water. The pigments were removed from the cells by the addition of methanol (AnalaR grade) and by heating to $50^{\circ} \mathrm{C}$ on a water bath for $5 \mathrm{~min}$. The extracts were clarified by centrifugation. The visible absorbance spectrum of each extract in methanol was determined in a Pye Unicam SP 1800 spectrophotometer equipped with an SP 1806 synchronized wavelength drive unit.

\section{RESULTS}

Numerical taxonomic analysis. The similarities between strains are illustrated in a dendrogram (Fig. 1) derived by median-sorting cluster analysis; the order of the strains was obtained from the minimum spanning tree. The strains of the new. species, which included the two strains of group IIk, biotype 1 , formed a homogeneous cluster at the $92.5 \%$ similarity level, and the majority of the strains (25/29) joined within the cluster at a similarity level of $95.5 \%$. Table 3 lists the average within- and between-taxon similarities of the new species, the three unclassified strains phenotypically similar to the new species, whose taxonomic position is discussed separately below, and of the 10 species or taxa (including group IIk, biotype 2) that were represented in the numerical analysis by two or more strains. The average within-taxon similarity of $93.4 \%$ for the new species was within the range of values determined for the other taxa (Table 3). The median organism of the new-species cluster was represented by two strains (CL1/70 and B3271) that were biochemically identical although they originated from different sources. Strains CL50/72 and A96/68 were the least typical members of the new species, and each differed from others of the cluster in two, but not the same two, biochemical characteristics (see Table 2). Xanthomonas campestris and Xanthomonas hyacinthi, each represented in this study by two strains which were not designated type strains, were the reference species most similar $(77.9 \%$, Table 3$)$ to the new species. Although 27 of the various other reference strains were type or suggested type strains (Table 1), insufficient strains of each species were included in the numerical analysis to draw any conclusions about their interrelationships.

Characteristics of the new species. The 29 strains, comprised of 27 field isolates and 2 strains of Weaver group IIk, biotype 1, were strictly aerobic, gram-negative rods, 0.7 by 1.4 $\mu \mathrm{m}$, with parallel sides and rounded ends. The 


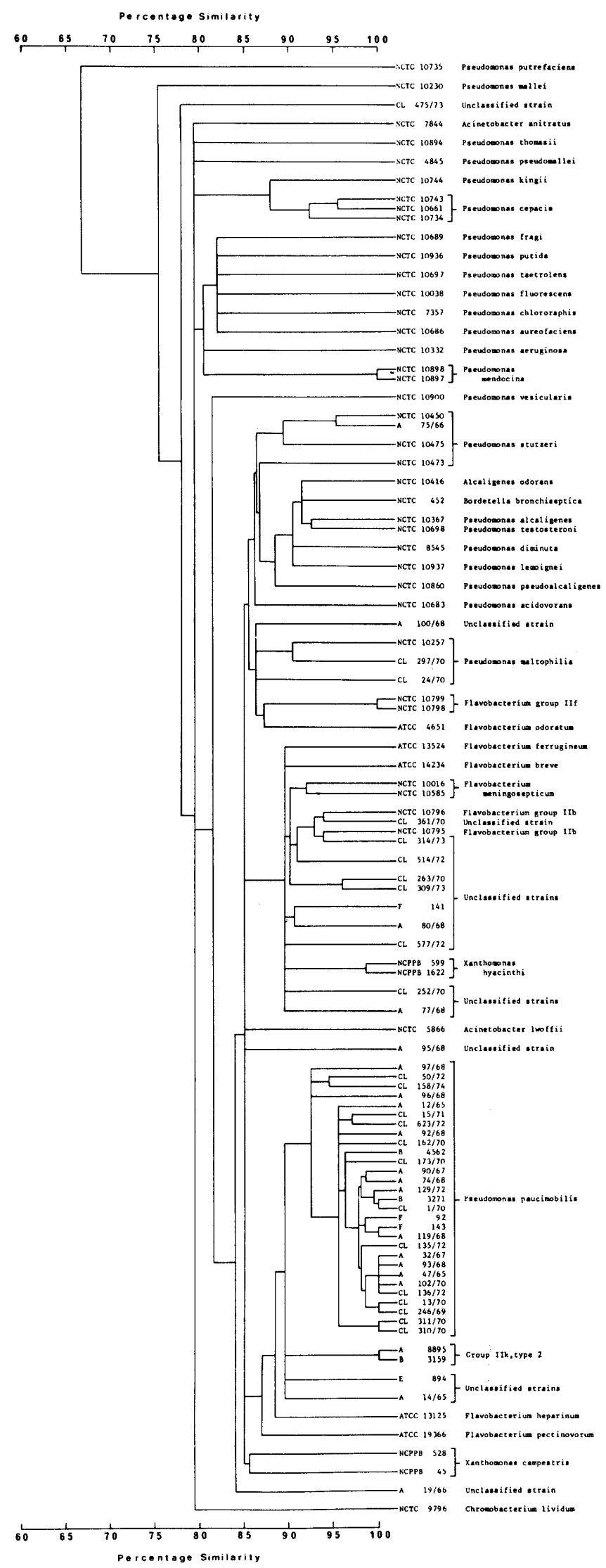

FIG. 1. Dendrogram based on median-sorting cluster analysis. Percentage similarity was calculated with the general similarity coefficient of Gower $\left(S_{G}\right)$, negative matches included. 


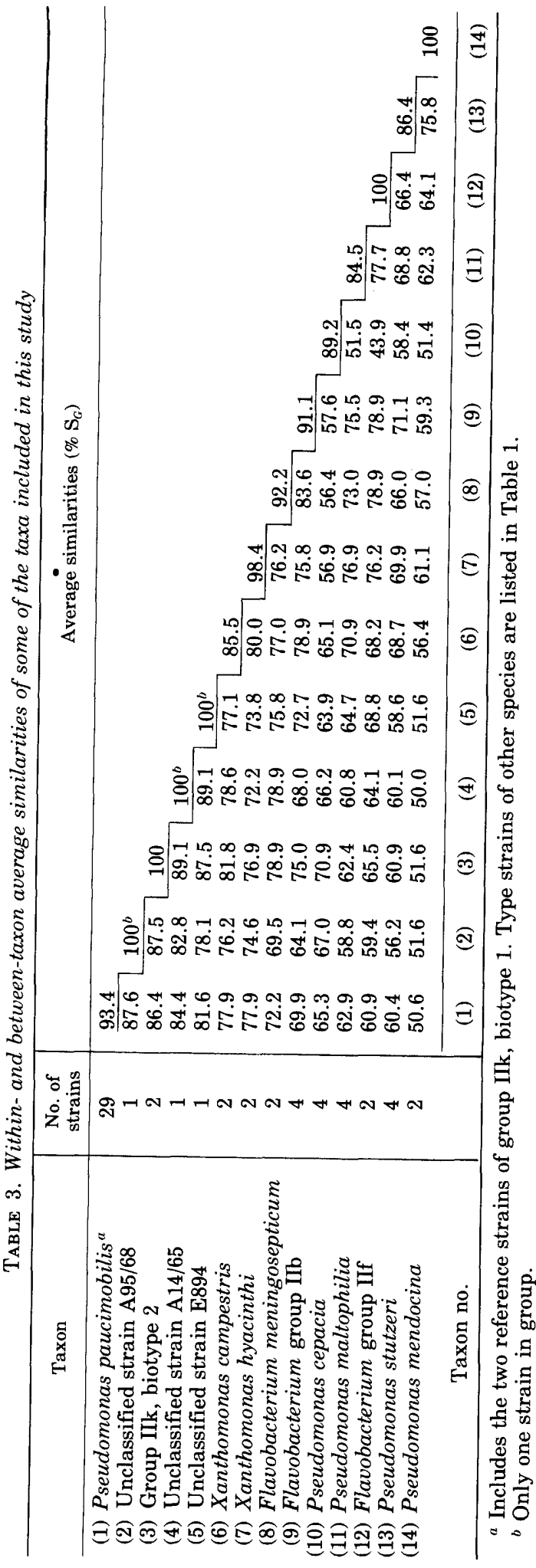

two median organisms (CL1/70 and B3271) and four other selected strains of the new species (CL158/74, A97/68, F92, and B4562) were tested for autotrophic growth and were found to be unable to grow either microaerophilically or in an atmosphere of hydrogen.

The colonies on nutrient agar after $48 \mathrm{~h}$ were circular, $1 \mathrm{~mm}$ in diameter, low convex, entire, smooth, and opaque. A yellow pigment was produced which did not diffuse in nutrient agar nor fluoresce on King medium B. The strains differed in their abilities to produce a dark brown pigment on tyrosine agar. The colonies were butyrous in consistency except for those of CL50/72, which were mucoid and viscid, and were easily emulsified in distilled water to give uniform suspensions except for the colonies of three strains (CL135/72, CL623/72, and A47/65), which formed rough suspensions.

The strains grew optimally at $30^{\circ} \mathrm{C}$, and all biochemical tests, unless specified otherwise, were carried out at this temperature. The strains grew at room temperature and at $37^{\circ} \mathrm{C}$ but not at 5 or $42^{\circ} \mathrm{C}$. Hemolysis was not obtained from aerobic growth on $5 \%$ ( $\mathrm{vol} / \mathrm{vol})$ horse blood agar. Growth in nutrient broth produced a moderate turbidity with the formation of a pellicle and a dense deposit after 2 to 3 days.

Motility was demonstrated in nutrient broth medium at room temperature for 22 of the 29 strains, although only a low percentage (approximately $5 \%$ ) of the bacteria were actively motile. All 29 strains of the new species were motile in the ARJ yeast extract medium at room temperature, and in all but 2 strains (CL623/72 and A102/70), a higher proportion (approximately $20 \%$ ) of the cells were actively motile. The proportion of motile cells was unchanged after serial subcultures (up to five) in the ARJ yeast extract medium. Only one strain (F92) was motile at room temperature and at $37^{\circ} \mathrm{C}$ (in nutrient broth). Six selected strains (CL1/70, CL136/72, CL158/74, F92, B3271, and B4562) were also cultured in semisolid agar at $22^{\circ} \mathrm{C}$. There was no evidence that cells of these strains spread through this medium or that subcultures in nutrient broth at $22^{\circ} \mathrm{C}$ from margins of the colonies had a significantly higher proportion of motile cells. When flagella were present the cells of CL1/70 (Fig. 2) and 26 other strains of the new species each had a single, polar flagellum; CL1/70 and 21 other strains were examined by electron microscopy here, and 5 strains (A47/65, A32/67, A90/67, A92/68, and A96/68) were examined previously by flagella staining and light microscopy (R. J. Owen, unpublished observations). The two strains (CL623/72 and A102/70) which did not 


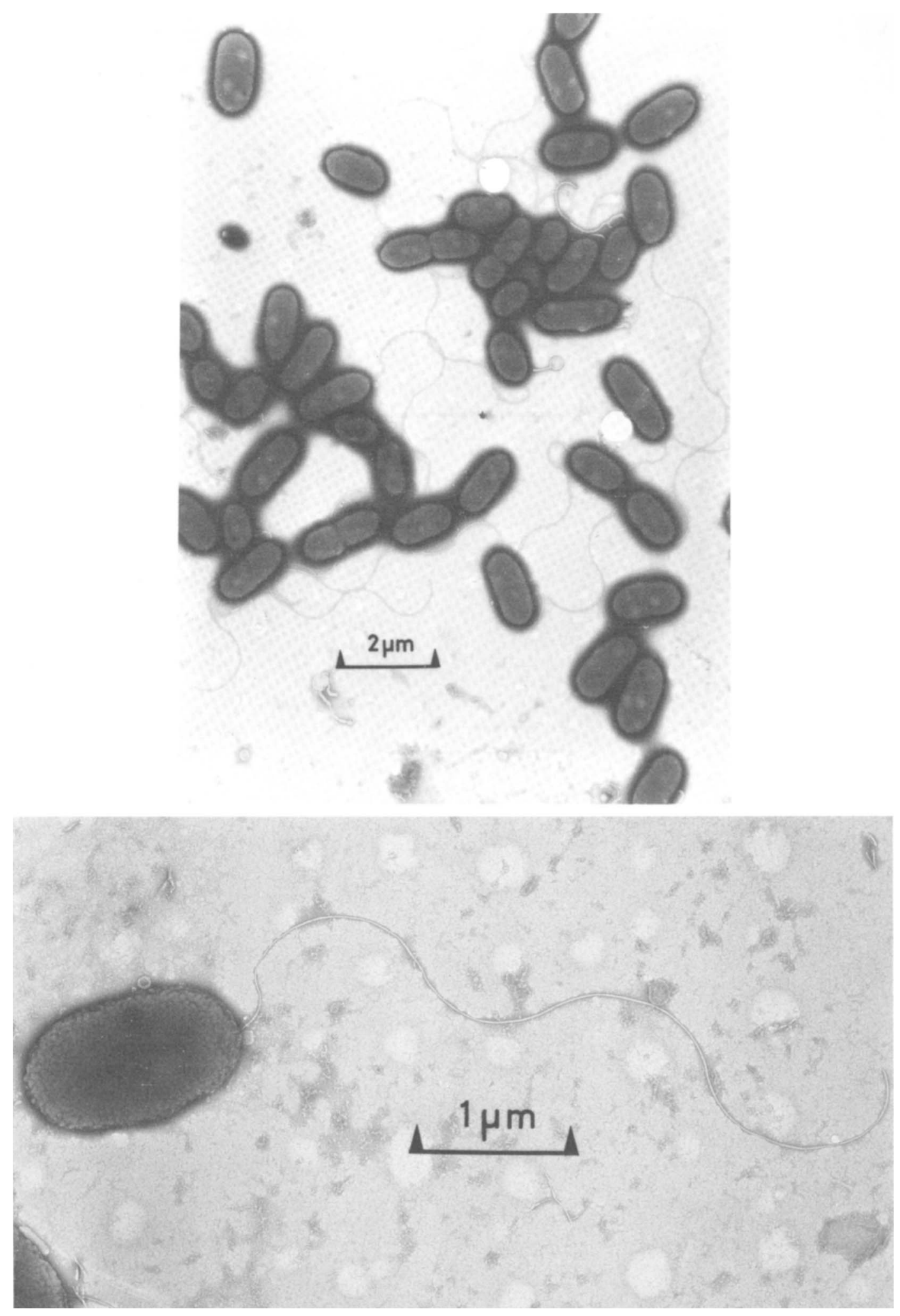

FIG. 2. Electron micrographs of the type strain (CL1/70) of the new species to show flagella arrangement. Preparations were stained with phosphotungstic acid. (a) CL1/70 showing flagellated and nonflagellated cells. (b) CL1/70 with a single polar flagellum. 
yield a higher proportion of motile cells in ARJ yeast extract medium at room temperature were examined by electron microscopy, but no flagellated cells were found.

The biochemical characteristics of the strains and their susceptibilities to antimicrobial agents are listed in Table 2. A total of 59 characteristics were common to all strains (either all positive or all negative), and there were 29 characteristics in which one or more of the strains differed. The tests with the largest number of strain differences were starch hydrolysis, motility in nutrient broth at room temperature, and susceptibility to carbenicillin and colistin.

DNA base composition. Table 4 lists the base compositions of 12 phenotypically representative strains of the new species. The values ranged from 64.2 to $66.9 \mathrm{~mol} \% \mathrm{G}+\mathrm{C}$, with a mean of $65.3 \mathrm{~mol} \%$ and a standard deviation of $\pm 1.0 \%$. Strain CL50/72, also in. Table 4, clustered with the new species in the numerical analysis, but it was least typical in biochemical and morphological characteristics and had a lower $\mathrm{G}+\mathrm{C}$ value $(61.5 \mathrm{~mol} \%)$. The mean and standard deviation of the $\mathrm{G}+\mathrm{C}$ content of the DNA of the new species, with this strain included, was $64.9 \pm 1.4 \mathrm{~mol} \%$.
Absorbance spectra of pigments. The pigment extracts in methanol from 10 strains (CL1/70, CL162/70, CL50/72, CL136/72, CL158/ 74, A92/68, A129/72, F92, B3271, and B4562) of the new species had absorbance peaks in the region 447 to $452 \mathrm{~nm}$ and 474 to $480 \mathrm{~nm}$, with a slight inflection at 420 to $430 \mathrm{~nm}$. Figure 3 shows that the spectrum of pigment from CL1/ 70 , the median organism of the new species, differed from that of the pigment of $X$. campestris NCPPB 528, which had a sharp absorbance peak at $448 \mathrm{~nm}$ and a broader peak in the 468 to $482 \mathrm{~nm}$ region.

Strains of uncertain taxonomic position. Several strains (taxon numbers $2,3,4$, and 5 in Table 3) had similarities to the new species but were excluded because they did not form a cluster with it at the $92.5 \%$ similarity level on the dendrogram derived from median sorting. The main characteristics that distinguished A95/68 from the strains of the new species were its failure to produce cytochrome oxidase and its ability to produce urease and to grow at $42^{\circ} \mathrm{C}$. However, this strain was included in the new species cluster by the single-linkage analysis, and it was similar to the new species in its $\mathrm{G}+\mathrm{C}$ content (Table 4) and in its pigment spectrum. The two strains of Weaver group IIk, biotype 2

TABLE 4. DNA base compositions of selected strains

\begin{tabular}{|c|c|c|c|c|}
\hline Strain & Designation & Buffer $^{a}$ & $T_{m} \pm \mathrm{SD}^{b}(\mathrm{C})$ & $\mathrm{G}+\mathrm{C}(\mathrm{mol} \%)$ \\
\hline CL50/72 & Pseudomonas paucimobilis & (I) & $80.7 \pm 0.10$ & $61.5^{c}$ \\
\hline CL158/74 & P. paucimobilis & (I) & $82.0 \pm 0.10$ & 64.2 \\
\hline CL310/70 & P. paucimobilis & (I) & $82.1 \pm 0.10$ & 64.4 \\
\hline CL311/70 & P. paucimobilis & (I) & $82.1 \pm 0.10$ & 64.4 \\
\hline B3271 & P. paucimobilis & (I) & $82.1 \pm 0.00$ & 64.4 \\
\hline B4562 & P. paucimobilis & (I) & $82.1 \pm 0.00$ & 64.4 \\
\hline $\mathrm{A} 47 / 65$ & P. paucimobilis & (II) & 93.3 & 64.9 \\
\hline CL1/70 & P. paucimobilis & (I) & $82.4 \pm 0.10$ & 65.0 \\
\hline $\mathrm{A} 93 / 68$ & P. paucimobilis & (II) & 93.5 & 65.4 \\
\hline $\mathrm{A} 12 / 65$ & P. paucimobilis & (II) & 93.6 & 65.6 \\
\hline $\mathrm{A} 96 / 68$ & P. paucimobilis & (I) & $82.8 \pm 0.00$ & 65.8 \\
\hline A90/67 & P. paucimobilis & (II) & 94.1 & 66.8 \\
\hline A97/68 & P. paucimobilis & (I) & $83.3 \pm 0.10$ & $\begin{array}{c}66.9 \\
64.9 \pm 1.4^{d}\end{array}$ \\
\hline A8895 & Group IIk, biotype 2 & (I) & $70.2 \pm 0.05$ & 39.6 \\
\hline B3159 & Group IIk, biotype 2 & (I) & $70.2 \pm 0.05$ & 39.6 \\
\hline E894 & Unclassified strain & (III) & $86.3 \pm 0.20$ & 41.3 \\
\hline A14/65 & Unclassified strain & (III) & $86.5 \pm 0.05$ & 41.8 \\
\hline A95/68 & Unclassified strain & (I) & $82.9 \pm 0.10$ & 66.0 \\
\hline NCTC $10537^{e}$ & Escherichia coli & (I) & $75.9 \pm 0.05$ & 51.5 \\
\hline
\end{tabular}

${ }^{a}$ Numbers in parentheses indicate the buffers used: (I) $0.015 \mathrm{M} \mathrm{NaCl}$ and $0.0015 \mathrm{M}$ trisodium citrate; (II) $0.1 \mathrm{M} \mathrm{NaCl}$ and $0.01 \mathrm{M}$ sodium phosphate; (III) $0.15 \mathrm{M} \mathrm{NaCl}$ and $0.015 \mathrm{M}$ trisodium citrate. Results for buffers II and III were determined in previous studies (R. Owen, unpublished observations). Details of the methods are described elsewhere (28).

${ }^{b} \mathrm{SD}$, Standard deviation.

c The equations used to calculate mol\% $\mathrm{G}+\mathrm{C}$ were as follows: buffer (I), mol\% $\mathrm{G}+\mathrm{C}=2.08 T_{m}-106.4$ (see text); buffer (II), mol\% G+C =2.36 $T_{m}-155.3$ (14); and buffer (III), mol\% G+C = 2.44 $T_{m}-169.3$ (6).

${ }^{d}$ Mean \pm SD for the above 13 strains.

${ }^{e}$ DNA reference strain. 


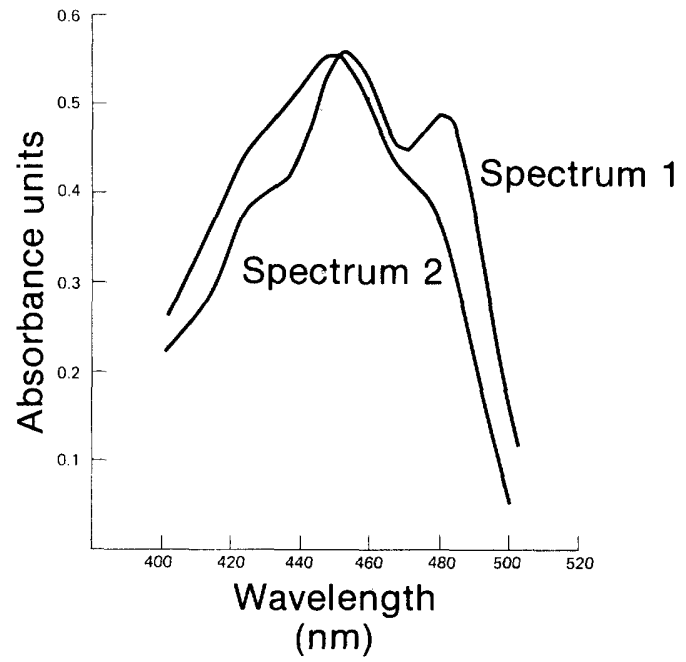

FIG. 3. Absorbance spectra in methanol of pigment extracts from the type strain (CL1/70) of the new species (spectrum 1) and Xanthomonas campestris NCPPB 528 (spectrum 2).

(A8895 and B3159), studied here and two other biochemically similar strains (A14/65 and E894) were not included in the new-species cluster by either method of cluster analysis, although all showed a high similarity ( $\geqslant 81.6 \%$, Table 3 ) to the new species. However, the four strains differed from those of the new species in several biochemical characteristics (see Table 5 for results of group IIk, biotype 2, strains) and were resistant to a wider range of antibiotics, which included amoxicillin, chloramphenicol, erythromycin, gentamicin, kanamycin, and novobiocin (B. Holmes, unpublished results). Also, with respect to the criterion of DNA base composition, these four strains were genetically different from the new species, as their $\mathrm{G}+\mathrm{C}$ contents were in the range 39.6 to $41.8 \mathrm{~mol} \%$ (Table 4). The minimum spanning tree showed that all five strains described above joined the new species through typical members of that cluster. These strains and 13 other yellow-pigmented isolates, which were unclassified except for the two strains corresponding to Flavobacterium sp. (King group IIb), will not be discussed further at this time.

\section{DISCUSSION}

The results of the cluster analysis and the within-group similarities presented above show that the 29 strains of yellow-pigmented bacteria, for which the name $P$. paucimobilis (pau -ci $\cdot \mathrm{mo}^{\prime}$ bi $\cdot$ lis. L. adj. paucus few; L.adj. mobilis mobile; M.L. fem. adj. paucimobilis intended to mean few cells motile) is here pro- posed, constitute a homogeneous and distinctive taxonomic group. These findings were corroborated by similarities among strains in their susceptibilities to antimicrobial agents and in the $\mathrm{G}+\mathrm{C}$ contents of their DNAs. This taxon included the two strains of Weaver group IIk, biotype 1, and one of these (B3271) held with CL1/70 the median position of the $P$. paucimobilis taxon. A comparison of the published results on group IIk $(32,33,35)$ with the results obtained here indicates that $P$. paucimobilis and Weaver group IIk, biotype 1, are identical taxa; this is supported by the fact that two strains of group IIk, biotype 1, were included in the $P$. paucimobilis cluster. However, on the basis of the information available to us, we can only assume that these two particular strains are representative of group IIk, biotype 1 .

The strains for which we propose the name $P$. paucimobilis conform to the definition of $\mathrm{Pseu}$ domonas given by Doudoroff and Palleroni (8): strictly aerobic, gram-negative rods that produce catalase and have a respiratory metabolism, are motile by means of polar flagella and have $\mathrm{G}+\mathrm{C}$ contents of their DNAs in the range of 58 to $70 \mathrm{~mol} \%$. Several isolates of yellowpigmented bacteria similar to our own and also from clinical sources have previously been assigned to the genus Xanthomonas $(15,29)$. However, our strains of $P$. paucimobilis differed from those of Xanthomonas in being strongly positive in the production of cytochrome oxidase (10), in their ability to grow in the presence of TTC (10), to utilize asparagine (10), and to produce acid from salicin (9), and in having minimal growth requirements that were not complex (10). There is evidence that Pseudomonas and Xanthomonas strains can be separated by numerical taxonomic methods (4) and by pigment-absorbance spectra (31), but there are very few biochemical characteristics, other than those described above, that can be used to distinguish the two genera. Our strains have, therefore, been classified in the genus Pseudomonas.

Yellow pigmentation is a characteristic of certain species of Pseudomonas (e.g., P. aureofaciens, $P$. cepacia, $P$. palleroni, and $P$. stutzeri), as well as of species of Xanthomonas. There were slight differences between the absorbance spectra of the pigments of typical $P$. paucimobilis strains and the strain of $X$. campestris studied here. However, we are uncertain of the taxonomic significance of these differences, as this characteristic was examined only in a small number of $P$. paucimobilis and of Xanthomonas strains, and the class of chemical compound to which the pigments belonged 


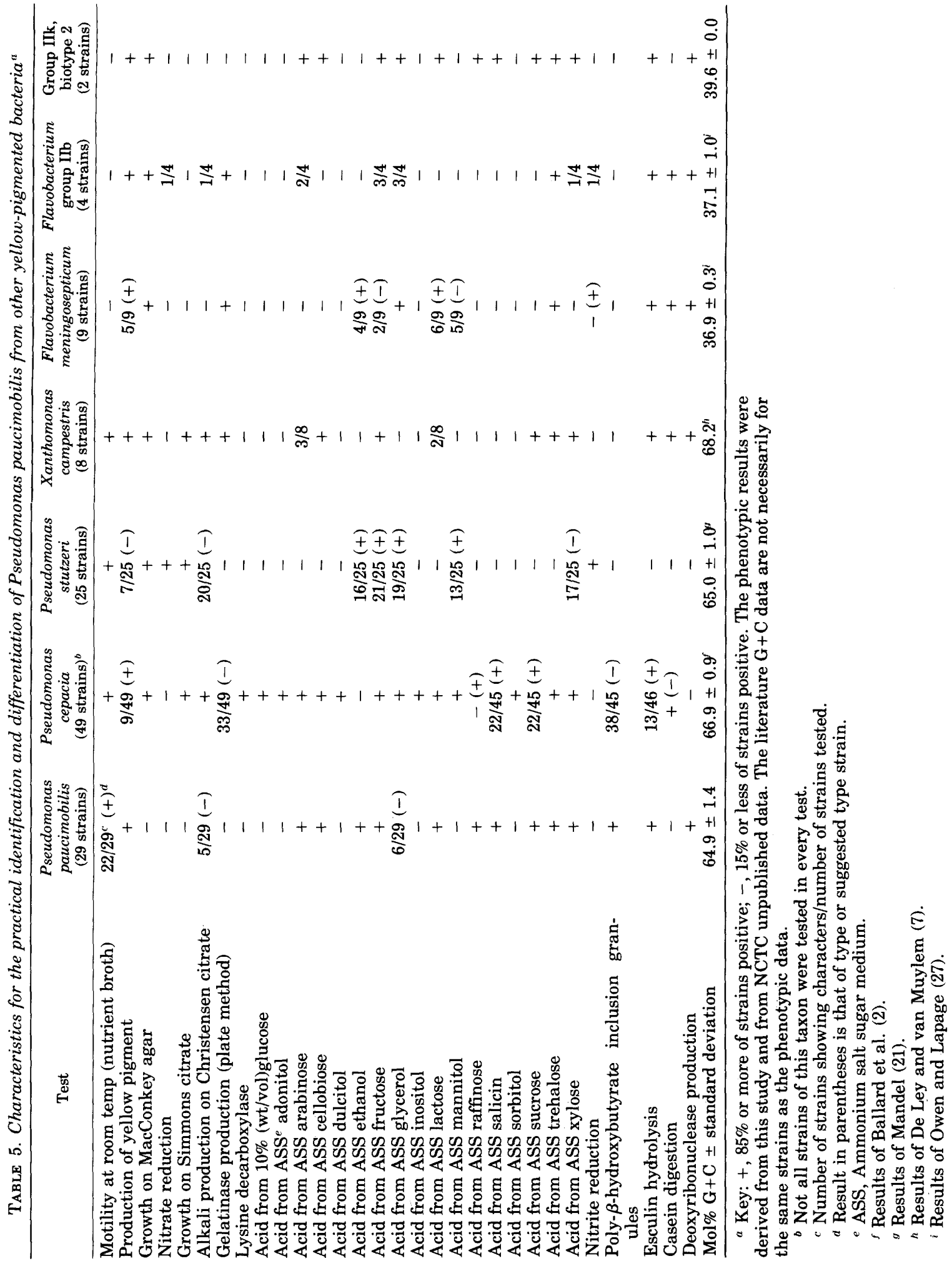


was not determined. The pigment results will not be discussed further at this time.

Since the type strain and the five other selected strains of $P$. paucimobilis did not grow autotrophically with hydrogen, we exclude the possibility that strains of the new species are "hydrogen bacteria." A strain (DSM 63) of $P$. palleroni, which is a yellow-pigmented species that grows autotrophically with hydrogen and has a $\mathrm{G}+\mathrm{C}$ content of approximately $66.8 \%$ (8), has been examined separately in our laboratory (B. Holmes, unpublished results) and was found to differ from strains of $P$. paucimobilis in 12 biochemical characteristics out of 68 tested.

Characteristics useful in the practical identification of $P$. paucimobilis and in the differentiation of strains of this taxon from those of $P$. cepacia, P. stutzeri, X. campestris, Flavobacterium meningosepticum, and Flavobacterium sp. (King group IIb), and group IIk, biotype 2, are recorded in Table 5. The results on $P$. cepacia and $P$. stutzeri were included because these two species have been encountered occasionally in clinical material and could be confused with $P$. paucimobilis because some strains produce a yellow pigment. $F$. meningosepticum and Flavobacterium $\mathrm{sp}$. (King group IIb) are included in the table because they are also yellow-pigmented bacteria that can occur in human clinical material $(27,35)$, the hospital environment, and water (25). The table includes group IIk, biotype 2 , and $X$. campestris, as these two groups of strains showed the highest phenetic similarity to $P$. paucimobilis .

There is no evidence that strains here placed in $P$. paucimobilis have been incriminated in any infection in man, although such strains have been isolated from a variety of clinical specimens and from sources in the hospital environment. The occurrence of the organism in respirators and similar equipment suggests imperfectly sterilized water as the primary source of contamination.

Description of the type strain. The characteristics of the type strain, CL1/70 (= NCTC 11030), also listed in Table 2, are as follows.

Gram-negative, nonsporeforming rods (average dimensions: $0.7 \mu \mathrm{m}$ in width by $1.4 \mu \mathrm{m}$ in length) of regular shape with rounded ends. Cells occur singly or in pairs. Motile at 18 to $22^{\circ} \mathrm{C}$ by means of a single polar flagellum; nonmotile at $37^{\circ} \mathrm{C}$. There is a low proportion of actively motile cells in nutrient broth medium at $22^{\circ} \mathrm{C}$.

Circular, low convex, smooth and entire colonies on nutrient agar after 2 days; colonies on $5 \%$ (vol/vol) horse blood agar are nonhemolytic; on nutrient agar, a yellow pigment is produced that has absorbance maxima in methanol at 452 and $479 \mathrm{~nm}$, with a slight inflection at $425 \mathrm{~nm}$, is water insoluble, and is not fluorescent. No brown pigment is produced on tyrosine agar.

Aerobic; there is no growth under anaerobic conditions.

Heterotrophic; incapable of autotrophic growth with molecular hydrogen as an electron donor.

Growth at $37^{\circ} \mathrm{C}$ but not at 5 or $42^{\circ} \mathrm{C}$. Optimum temperature: about $30^{\circ} \mathrm{C}$.

Catalase, cytochrome oxidase, and deoxyribonuclease are produced.

Urease is not produced.

$\mathrm{KCN}$ is not tolerated at a concentration of $0.0075 \%$ (wt/vol).

Tween 20 and Tween 80 are hydrolyzed. Opalescence on lecithovitellin agar is not produced.

Nitrate is not reduced to nitrite; nitrite is not reduced.

Indole and hydrogen sulfide are not produced.

Grows on $\beta$-hydroxybutyrate and in the presence of TTC but not on MacConkey agar or cetrimide agar. Lipid inclusion granules presumed to be poly- $\beta$-hydroxybutyrate are produced.

Casein is not digested and gelatin is not liquefied.

Esculin, starch, and tyrosine are hydrolyzed.

Minimal requirements for growth are not complex.

L-Asparagine is utilized. Citrate and malonate are not utilized.

Gluconate is not oxidized.

Arginine dihydrolase, arginine desimidase, lysine decarboxylase, and ornithine decarboxylase are not produced.

3 -Ketolactose is not produced.

Selenite is not reduced.

$\beta$-Galactosidase is produced.

Acid is produced in ammonium salt medium under aerobic conditions from arabinose, cellobiose, ethanol, fructose, glucose, lactose, maltose, raffinose, salicin, sucrose, trehalose, and xylose.

Acid is not produced in ammonium salt medium under aerobic conditions from adonitol, dulcitol, inositol, mannitol, sorbitol, glycerol, or rhamnose or from $10 \%$ (wt/vol) glucose and $10 \%$ (wt/vol) lactose.

Neither acid nor gas is produced from glucose in peptone water medium; acid is not produced from glucose in either the open or the closed tube of Hugh and Leifson O-F test medium.

Susceptible to ampicillin (200 $\mu \mathrm{g}$ per strip), carbenicillin (200 $\mu \mathrm{g}$ per strip), colistin $(1,000$ 
$\mu \mathrm{g}$ per strip), chloramphenicol (60 $\mu$ g per strip), erythromycin (10 $\mu$ g per disk), cephalexin (100 $\mu \mathrm{g}$ per strip), amoxicillin (200 $\mu$ g per strip), gentamicin (60 $\mu$ g per strip), kanamycin $(1,000$ $\mu \mathrm{g}$ per strip), tetracycline (500 $\mu \mathrm{g}$ per strip), and novobiocin (5 $\mu \mathrm{g}$ per disk). Resistant to streptomycin (500 $\mu \mathrm{g}$ per strip), nalidixic acid (30 $\mu \mathrm{g}$ per disk), penicillin G (4 IU per disk), polymyxin $\mathrm{B}$ ( $300 \mathrm{IU}$ per $\mathrm{ml}$ ), and vibriostatic agent $0 / 129$ phosphate $(1 \mu \mathrm{g}$ per $\mathrm{ml}$ ).

Guanine-plus-cytosine content of DNA: 65.0 mol\% ( $T_{m}$ estimation).

Source: isolated from a respirator.

Two additional strains of $P$. paucimobilis have been deposited in the National Collection of Type Cultures: NCTC 11031 and NCTC 11032 (Weaver group IIk, biotype 1, strains B3271 and B4562, respectively).

\section{ACKNOWLEDGMENTS}

We thank D. Claus for testing our strains for autotrophic growth, A. A. Porter for the electron microscopy, and R. E. Weaver and other investigators in different laboratories who kindly sent us strains. S. P. Lapage and L. R. Hill are thanked for their advice and helpful discussions, as are Pauline Roberts and J. Bradbury for their helpful comments on the xanthomonads. The Department of Health and Social Security is thanked for the grant that made this work possible.

\section{REPRINT REQUESTS}

Reprints are not available.

\section{LITERATURE CITED}

1. Anderson, E. S., and E. J. Threlfall. 1974. The characterization of plasmids in the enterobacteria. J. Hyg. 72:471-487.

2. Ballard, R. W., N. J. Palleroni, M. Doudoroff, R. Y. Stanier, and M. Mandel. 1970. Taxonomy of the aerobic pseudomonads: Pseudomonas cepacia, $P$. marginata, $P$. alliicola and P. caryophylli. J. Gen. Microbiol. 60:199-214.

3. Burnett, G. W., M. J. Pelczar, Jr., and H. J. Conn. 1957. Preparation of media, p. 37-63. In H. J. Conn (ed.), Manual of microbiological methods. McGrawHill Book Co. Inc., New York.

4. Colwell, R. R., and J. Liston. 1961. Taxonomic analysis with the electronic computer of some Xanthomonas and Pseudomonas species. J. Bacteriol. 82:913-919.

5. Cowan, S. T. 1974. Cowan and Steel's manual for the identification of medical bacteria, 2 nd ed. University Press, Cambridge.

6. De Ley, J. 1970. Reexamination of the association between melting point, buoyant density, and chemical base composition of deoxyribonucleic acid. J. Bacteriol. 101:738-754.

7. De Ley, J., and J. van Muylem. 1963. Some applications of deoxyribonucleic acid base composition in bacterial taxonomy. Antonie van Leeuwenhoek J. Microbiol. Serol. 29:344-358

8. Doudoroff, M., and N. J. Palleroni. 1974. Genus I. Pseudomonas Migula 1894, p. 217. In R. E. Buchanan and N. E. Gibbons (ed.), Bergey's manual of determinative bacteriology, 8 th ed. The Williams and Wilkins Co., Baltimore.

9. Dye, D. W. 1962. The inadequacy of the usual determinative tests for the identification of Xanthomonas spp. N. Z. J. Sci. 5:393-416.

10. Dye, D. W., and R. A. Lelliott. 1974. Genus II. Xan thomonas Dowson 1939, p. 243. In R. E. Buchanan and N. E. Gibbons (ed.), Bergey's manual of determinative bacteriology, 8 th ed. The Williams and Wilkins Co., Baltimore.

11. Gower, J. C. 1967. A comparison of some methods of cluster analysis. Biometrics 23:623-637.

12. Gower, J. C. 1971. A general coefficient of similarity and some of its properties. Biometrics 27:857-874.

13. Gower, J. C., and G. J. S. Ross. 1969. Minimum spanning trees and single linkage cluster analysis. Appl. Stat. 18:54-64.

14. Gratzer, W. B., L. R. Hill, and R. J. Owen. 1970. Circular dichroism of DNA. Eur. J. Biochem. 15:209214.

15. Greaves, P. W. 1966. Isolation of bacteria resembling Flavobacterium meningosepticum from human material in Britain. J. Med. Lab. Technol. 23:115-118.

16. Hill, L. R. 1968. The determination of deoxyribonucleic acid base compositions and its application to bacterial taxonomy, p. 177-186. In B. M. Gibbs and D. A. Shapton (ed.), Identification methods for microbiologists, part B. Academic Press, Inc. London.

17. Holmes, B., S. P. Lapage, and H. Malnick. 1975. Strains of Pseudomonas putrefaciens from clinical material. J. Clin. Pathol. 28:149-155.

18. King, E. O., M. K. Ward, and D. E. Raney. 1954. Two simple media for the demonstration of pyocyanin and fluorescin. J. Lab. Clin. Med. 44:301-307.

19. Lapage, S. P., and W. R. Willcox. 1974. A simple method for analysing binary data. J. Gen. Microbiol. 85:376-380.

20. Leifson, E. 1962. The bacterial flora of distilled and stored water. I. General observations, techniques and ecology. Int. Bull. Bacteriol. Nomen. Taxon. 12:133153.

21. Mandel, M. 1966. Deoxyribonucleic acid base composition in the genus Pseudomonas. J. Gen. Microbiol. 43:273-292.

22. Marmur, J. 1961. A procedure for the isolation of deoxyribonucleic acid from micro-organisms. J. Mol. Biol. 3:208-218.

23. Marmur, J., and P. Doty. 1962. Determination of the base composition of deoxyribonucleic acid from its thermal denaturation temperature. J. Mol. Biol. 5:109-118.

24. McEntegart, M. G., and A. Clark. 1973. Colonisation of dental units by water bacteria. Br. Dent. J. 134:140142.

25. Olsen, H. 1969. Flavobacterium meningosepticum isolated from outside hospital surroundings and during routine examination of patient specimens. Acta $\mathrm{Pa}$ thol. Microbiol. Scand. 75:313-322.

26. Owen, R. J., L. R. Hill, and S. P. Lapage. 1969. Determination of DNA base compositions from melting profiles in dilute buffers. Biopolymers 7:503-516.

27. Owen, R. J., and S. P. Lapage. 1974. A comparison of strains of King's group II-b of Flavobacterium with Flavobacterium meningosepticum. Antonie van Leeuwenhoek J. Microbiol. Serol. 40:255-264.

28. Pedersen, M. M., E. Marso, and M. J. Pickett. 1970 Nonfermentative bacilli associated with man. III. Pathogenicity and antibiotic susceptibility. Am. J. Clin. Pathol. 54:178-192.

29. Pickett, M. J., and M. M. Pedersen. 1970. Characterization of saccharolytic nonfermentative bacteria associated with man. Can. J. Microbiol. 16:351-362.

30. Sneath, P. H. A., and R. R. Sokal. 1973. Numerical taxonomy. Freeman and Co., San Francisco.

31. Starr, M. P., and W. L. Stephens. 1964. Pigmentation and taxonomy of the genus Xanthomonas. J. Bacteriol. 87:293-302.

32. Tatum, H. W., W. H. Ewing, and R. E. Weaver. 1974. 
Miscellaneous gram-negative bacteria, p. 270. In E. H. Lennette, E. H. Spaulding, and J. P. Truant (ed.), Manual of clinical microbiology, 2nd ed. American Society for Microbiology, Washington, D.C.

33. von Graevenitz, A. 1971. Economical system for the identification of non-fermentative Gram-negative rods. Antonie van Leeuwenhoek J. Microbiol. Serol. 37:201-208.
34. von Graevenitz, A. 1973. Clinical microbiology of unusual Pseudomonas species. Prog. Clin. Pathol. 5:185-218.

35. Weaver, R. E., H. W. Tatum, and D. G. Hollis. 1972. The identification of unusual pathogenic Gram-negative bacteria (Elizabeth 0 . King). Preliminary revision. Center for Disease Control monograph, Atlanta, $\mathrm{Ga}$. 